\title{
International Repercussions of Direct Taxes
}

\author{
Wolfgang Eggert*
}

13.9 .98

\begin{abstract}
This paper analyzes the impact of tax competition between two countries of unequal per-capita capital endowments on tax rates and efficiency when distorting wage, residence-based and source-based capital taxes (or any combination of two instruments) are available for governments. The national welfare costs and benefits of tax rate variations are shown to be ambiguous in the asymmetric Nash equilibrium due to the existence of tax base and terms of trade effects. Moreover, numerical simulation results indicate that non-cooperative equilibria in Nash strategies are inefficient from an international perspective, even if residence-based capital taxes are in the set of tax instruments available to fiscal authorities.
\end{abstract}

JEL Classification: H2, H4, H7

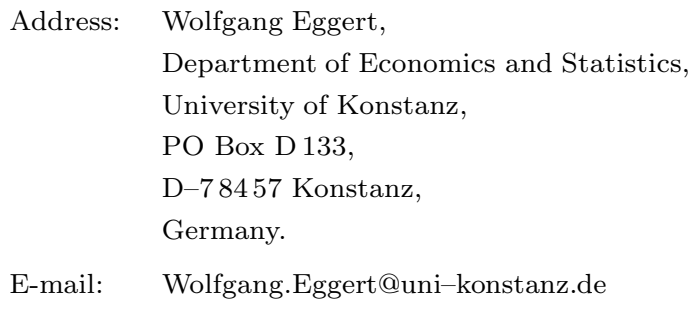

\footnotetext{
* Paper presented at the 1998 conference of the International Institute of Public Finance in Córdoba, Argentinia. I am grateful to seminar participants and to Harry Huizinga for helpful comments. All remaining shortcomings are mine.
} 


\section{Introduction}

Capital tax competition has long been an issue in the theoretical literature. The early models stress the negative consequences of non-cooperative tax setting on welfare and predict an underprovision of local public goods in the symmetric Nash equilibrium between identical countries [Zodrow and Mieszkowski (1986); Wildasin (1989)]. In these models, owners of mobile capital shift away their resources from high-tax to low-tax countries, offering a more favorable tax climate. Governments perceive a harmful capital outflow caused by sourcebased capital taxes in the non-cooperative equilibrium, which raises marginal cost of public funds and reduces public expenditures at an inefficient low level.

A first counterexample against the result that Nash strategies lead to an inefficient equilibrium is made by Frenkel, Razin and Sadka (1991) in a two-period model with endogenous labor supply. Basically, their main conclusion is that a tax competition equilibrium between small countries is constrained efficient if residence-based capital taxes are available for fiscal authorities. This efficiency result has been extended by Bucovetsky and Wilson (1991) to the case of a symmetric Nash equilibrium in source-based and residence-based capital taxes between (equal) non-price-taking countries. The Nash equilibrium also is efficient if taxes on the incomes of all factors subject to choice by households (i.e. labor and residence-based capital taxes) are available for fiscal authorities [cf. Eggert (1998)]. As is well-known by now, results are strongly related to the Diamond-Mirrlees (1971) Production Efficiency lemma that the closed economy's equilibrium should be on the frontier of the aggregate production set if a sufficient set of fiscal instruments is available [cf. Eggert and Haufler (1998)].

The aforementioned literature considers symmetric Nash equilibria. The assumption of identical countries has been relaxed by several authors who focused on different population sizes as an important determinant of international differences in tax rates provoked by variable perceived tax elasticities. Bucovetsky (1991) and Wilson (1991) prove that a small country undercuts its large neighbor and benefits from non-cooperation. Since the smaller of two otherwise identical countries is able to cut into the larger country's tax base it has the higher per-capita welfare in the Nash equilibrium compared to the case of full coordination. However, the assumptions of the Production Efficiency lemma can be fulfilled when countries only differ in population sizes so that a decentral Nash equilibrium does not have to be inefficient. The argument is that there exists no motive for trade in capital in these models, except for differences in tax rates. Hence, tax policies of governments are characterized as internationally efficient if, and only if, they replicate the benchmark tax structure of the closed economy. It is rather straightforward then from the Production Efficiency theorem that governments of countries which only differ in population sizes have the necessary incentives to internalize fiscal externalities in their self-interest, provided that 
fiscal authorities have access to the incomes of all factors subject to choice by households. Just as in the case of large (but identical) countries discussed above, an efficient equilibrium can be established when taxes on wages and worldwide capital income are available.

Thus it is a relevant question to investigate into the strategic effects of capital taxation when countries differ in their per-capita capital endowments and the Production Efficiency lemma is not applicable because each government faces a different budget constraint. ${ }^{1} \mathrm{We}$ set up a two-period-two-country model with endogenous labor supply where governments have an (in)complete set of three tax instruments at their disposal: (i) a tax on labor income, (ii) a tax on worldwide interest income of their residents and (iii) a tax on the capital stock invested within their borders. In addition to the tax base effects discerned in symmetric tax competition models, terms of trade effects are observed in the asymmetric Nash equilibrium where pecuniary externalities prevail in addition to fiscal externalities [cf. DePater and Myers (1994)]. The three tax instruments considered in the analysis affect the net capital balance of a country in quite different ways and therefore have a variable strategic importance: The source-based capital tax reduces national capital demand, whereas the residence-based capital tax distorts capital supply decisions of residents. The wage tax distorts the national labor market, tends to increase the marginal productivity of capital (due to the reduction in labor supplied) and hence has an indirect effect on the net capital balance.

Intuitively follows from that reasoning that the tax structure in a capital exporting country differs from the tax structure in a capital importing country. Since international differences in tax rates depict a reason for inefficient capital reallocations, the arguments in favor of residence-based capital taxes derived from symmetric tax competition models are a priori not transferable to the case of large countries which differ in their per-capita capital endowments.

In the paper we use both theoretical and numerical methods to gain some first insights into the question which international repercussions of distorting tax systems can be expected in the Nash equilibrium between unequal countries. In a first section the model is set up and non-cooperative tax structures are derived. It then goes to discuss the components of the non-cooperative tax rules, i.e. the tax base and terms of trade effects provoked by the tax instruments. The next section turns to a numerical analysis of the welfare implications of international competition. Our simulation results indicate that local public goods in some cases are provided at an inefficient high level. But this result critically depends (i) on the fiscal environment under consideration, i.e. the set of available tax instruments, and it is

\footnotetext{
${ }^{1}$ In a recent paper Keen and Piekkola (1997) derive guidelines for international tax policy when there exist untaxed pure profits and yet another condition of the Production Efficiency is violated. Homburg (1998) distinguishes between a national and an international version of the production efficiency theorem. Basically, the first requires production taxes to vanish, the latter internationally harmonized source-based capital taxes.
} 
(ii) also determined by the sign of the country's net capital balance. As a general result, Nash equilibria prove to be inefficient in all asymmetric cases regardless of the availability of residence-based capital taxes.

\section{The Model}

In this first section we develop a model similar to Bucovetsky and Wilson (1991) which is extended for international differences in factor endowments, but we restrict our analysis to the two-country case. In the two-period model individual agents in both countries are assumed to maximize a utility function which is separable between private and public goods: ${ }^{2}$

$$
U\left(x_{1}, x_{2}, F\right)+\tilde{U}(g)
$$

where $x_{1}$ and $x_{2}$ denote private consumption in period one and two, $F$ is leisure consumed in the second period, and $g$ is the supply of a local public good. Due to the usual separability assumption goods consumed are independent of the level of public good supply, which is determined by the government and thus exogenous from the perspective of the consumer. Residents are price-takers and choose their levels of private consumption to maximize utility subject to the two-period budget constraint:

$$
x_{1}+\frac{x_{2}}{r-t^{r}}=\frac{w-t^{w}}{r-t^{r}}(T-F)+e,
$$

where

$$
\left(r-t^{r}\right)=\text { rate of interest, } r \text {, net of the residence-based capital tax, } t^{r},
$$

$\left(w-t^{w}\right)=$ gross wage rate, $w$, net of the wage tax, $t^{w}$,

$\left(y-x_{1}\right)=$ savings, equivalent to capital supplied by residents, $s$,

$(T-F)=$ labor supply, $L$,

$e, T=$ initial resource and time endowments.

Using the utility function (2.1) and the definitions introduced in the description of the private resource constraint (2.2) gives the Lagrangean:

$$
\mathcal{L} \equiv U\left(e-s, x_{2}, T-L\right)-\lambda\left[x_{2}-\left(w-t^{w}\right) L-\left(r-t^{r}\right) s\right]
$$

\footnotetext{
${ }^{2}$ For notational convenience we can drop-out country-specific indices in most of the equations in this section without a loss of information.
} 
We solve the problem defined above in the usual way and arrive at the standard first-order conditions which determine utility maximizing labor and capital supply:

$$
\begin{aligned}
& \frac{\partial \mathcal{L}}{\partial s}=-U_{s}+\lambda\left(r-t^{r}\right)=0, \\
& \frac{\partial \mathcal{L}}{\partial x_{2}}=U_{x}-\lambda=0, \\
& \frac{\partial \mathcal{L}}{\partial L}=-U_{l}+\lambda\left(w-t^{r}\right)=0, \\
& \frac{\partial \mathcal{L}}{\partial \lambda}=\left(w-t^{w}\right) L+\left(r-t^{r}\right) s-x_{2}=0 .
\end{aligned}
$$

Applying the implicit function theorem to these conditions it can readily be shown that price effects on labor supply, $L(\cdot)$, and savings functions, $s(\cdot)$, generally are ambiguous in sign due to the interaction of income and cross-price substitution effects.

Therefore, we use compensated labor supply, $\mathfrak{L}(\cdot)$, and savings functions, $\mathfrak{s}(\cdot)$, for some of the analysis. From the second-order conditions of the utility optimization problem follows that own-price effects of compensated factor supply are positive, and the symmetry of the Slutsky matrices implies equality of all compensated cross-price elasticities. In line with Bucovetsky and Wilson (1991) we assume that leisure is a Hicksian substitute with first period's consumption. It follows that:

$$
\mathfrak{s}_{r}>0, \quad \mathfrak{L}_{w}>0, \quad \mathfrak{s}_{w}=\mathfrak{L}_{r}<0,
$$

where subscripts denote partial derivatives. It will prove helpful to decompose uncompensated effects using Slutsky equations. This establishes the following relationship between uncompensated and Hicksian derivatives:

$$
\begin{aligned}
& \phi \equiv s L_{w}-L L_{r}=s \mathfrak{L}_{w}-L \mathfrak{L}_{r} \\
& \psi \equiv L s_{r}-s s_{w}=L \mathfrak{s}_{r}-s \mathfrak{s}_{w}
\end{aligned}
$$

The productive sector of each country is described by a constant-returns-to-scale production function, $f(k, l)$, which relates each country's output to the level of capital, $k(\cdot)$, and labor, $l(\cdot)$, invested and employed in the country. The technology exhibits the usual properties $f_{k}>0, f_{l}>0, f_{k k}<0, f_{l l}<0$. Again, subscripts denote partial derivatives. Normalizing the price of output to equal one, the familiar zero-profit condition is given by:

$$
f(k, l)-\left(r+t^{s}\right) k-w l=0 .
$$

where we introduced the source-based capital tax $t^{s}$ as a third tax instrument. In accordance with the capital tax competition literature, the source-based capital tax, $t^{s}$, is levied on 
all capital invested in the home economy. The first-order conditions for labor and capital demanded by firms are:

$$
\begin{aligned}
f_{l}-w & =0, \\
f_{k}-\left(r+t^{s}\right) & =0 .
\end{aligned}
$$

As the labor and capital markets are competitive, profit maximization in the choice of labor and capital by firms implies that marginal products of labor and capital must be equated to their marginal costs. Applying the implicit-function rule to (2.6) and using (2.7) yields a negatively-sloped factor price frontier:

$$
\frac{\partial w}{\partial r}=-\frac{k}{l}
$$

Finally we differentiate (2.6) with respect to $k$ and $l$, which makes the second-order crossderivatives of the production function expressible as:

$$
\begin{aligned}
& f_{l k}=-f_{k k} \frac{k}{l}, \\
& f_{k l}=-f_{l l} \frac{l}{k} .
\end{aligned}
$$

We now turn to the public sector. According to our definition of unit taxes, the public resource constraint is given by:

$$
R \equiv t^{w} L+t^{r} s+t^{s} k-c(g)=0,
$$

where $c(g)$ denotes the per-capita cost function of the local public good. We assume that each government chooses tax rates in order to maximize the representative individual's indirect utility function:

$$
V \equiv U\left(e-s\left(t^{s}, t^{r}, t^{w}\right), x_{2}\left(t^{s}, t^{r}, t^{w}\right), T-L\left(t^{s}, t^{r}, t^{w}\right)\right)+\tilde{U}(g),
$$

subject to the public resource constraint (2.10). The Lagrangean of the problem:

$$
\mathcal{W} \equiv V(\ldots)-\Lambda R
$$

is supposed to be strictly concave in each of the tax instruments. We differentiate (2.12) with respect to tax rates $t^{s}, t^{r}, t^{w}$ and $g$ and yield the first-order conditions for the government's problem:

$$
\begin{aligned}
& \frac{\partial \mathcal{W}}{\partial t^{s}}=-U_{s} \frac{\partial s}{\partial t^{s}}+U_{x} \frac{\partial x}{\partial t^{s}}-U_{l} \frac{\partial L}{\partial t^{s}}-\Lambda k-\Lambda k\left(\frac{\partial L}{\partial t^{s}} \frac{t^{w}}{k}+\frac{\partial s}{\partial t^{s}} \frac{t^{r}}{k}+\frac{\partial k}{\partial t^{s}} \frac{t^{s}}{k}\right)=0 \\
& \frac{\partial \mathcal{W}}{\partial t^{r}}=-U_{s} \frac{\partial s}{\partial t^{r}}+U_{x} \frac{\partial x}{\partial t^{r}}-U_{l} \frac{\partial L}{\partial t^{r}}-\Lambda s-\Lambda s\left(\frac{\partial L}{\partial t^{r}} \frac{t^{w}}{s}+\frac{\partial s}{\partial t^{r}} \frac{t^{r}}{s}+\frac{\partial k}{\partial t^{r}} \frac{t^{s}}{s}\right)=0 \\
& \frac{\partial \mathcal{W}}{\partial t^{w}}=-U_{s} \frac{\partial s}{\partial t^{w}}+U_{x} \frac{\partial x}{\partial t^{w}}-U_{l} \frac{\partial L}{\partial t^{w}}-\Lambda L-\Lambda L\left(\frac{\partial L}{\partial t^{w}} \frac{t^{w}}{L}+\frac{\partial s}{\partial t^{w}} \frac{t^{r}}{L}+\frac{\partial k}{\partial t^{w}} \frac{t^{s}}{L}\right)=0, \\
& \frac{\partial \mathcal{W}}{\partial g}=\tilde{U}_{g}+\Lambda c_{g}=0 .
\end{aligned}
$$


For later purpose we use the slope of the factor price frontier (2.8), the labor market clearing condition $L=l$ and $(2.4 \mathrm{~b})$ after differentiation of $(2.4 \mathrm{~d})$, which gives:

$$
\begin{aligned}
k & =-\frac{\partial x_{2}}{\partial t^{s}}+\left(r-t^{r}\right) \frac{\partial s}{\partial t^{s}}+\left(w-t^{w}\right) \frac{\partial L}{\partial t^{s}} \\
s & =-\frac{\partial x_{2}}{\partial t^{r}}+\left(r-t^{r}\right) \frac{\partial s}{\partial t^{r}}+\left(w-t^{w}\right) \frac{\partial L}{\partial t^{r}} \\
L & =-\frac{\partial x_{2}}{\partial t^{w}}+\left(r-t^{r}\right) \frac{\partial s}{\partial t^{w}}+\left(w-t^{w}\right) \frac{\partial L}{\partial t^{w}} .
\end{aligned}
$$

In the next step we use equations (2.14) and apply (2.4) to the first-order conditions of the government's optimization problem (2.13), which yields:

$$
\begin{aligned}
& \frac{\partial \mathcal{W}}{\partial t^{s}}=-U_{x} k-\Lambda k-\Lambda k\left(\frac{\partial L}{\partial t^{s}} \frac{t^{w}}{k}+\frac{\partial s}{\partial t^{s}} \frac{t^{r}}{k}+\frac{\partial k}{\partial t^{s}} \frac{t^{s}}{k}\right)=0, \\
& \frac{\partial \mathcal{W}}{\partial t^{r}}=-U_{x} s-\Lambda s-\Lambda s\left(\frac{\partial L}{\partial t^{r}} \frac{t^{w}}{s}+\frac{\partial s}{\partial t^{r}} \frac{t^{r}}{s}+\frac{\partial k}{\partial t^{r}} \frac{t^{s}}{s}\right)=0, \\
& \frac{\partial \mathcal{W}}{\partial t^{w}}=-U_{x} l-\Lambda L-\Lambda L\left(\frac{\partial L}{\partial t^{w}} \frac{t^{w}}{L}+\frac{\partial s}{\partial t^{w}} \frac{t^{r}}{L}+\frac{\partial k}{\partial t^{w}} \frac{t^{s}}{L}\right)=0, \\
& \frac{\partial \mathcal{W}}{\partial g}=\tilde{U}_{g}+\Lambda c_{g}=0,
\end{aligned}
$$

Due to the separability assumption in the utility function we can think of the fiscal decision captured by (2.15) as taking place in two stages: first the government sets public consumption to satisfy the modified Samuelson condition (2.15d); then the government chooses tax rates according to (2.15a)-(2.15c). In the following we concentrate on the second stage of the optimization process where tax rates are determined.

Let $\epsilon_{k}, \epsilon_{s}, \epsilon_{l}$ denote the general equilibrium effects of taxes on the tax bases, which we define as the negative of the terms in brackets in (2.15). Then system (2.15) simplifies to (with instruments shown in parenthesis):

$$
\begin{aligned}
\left(t^{s}\right): & & -\Lambda=U_{x} /\left(1-\epsilon_{k}\right), \\
\left(t^{r}\right): & & -\Lambda=U_{x} /\left(1-\epsilon_{s}\right), \\
\left(t^{w}\right): & & -\Lambda=U_{x} /\left(1-\epsilon_{l}\right) .
\end{aligned}
$$

Using (2.16) it is easy to describe any tax reform which either replaces one particular tax by another or finances a marginal unit of additional public good supply by increasing a tax.

In the subsequent analysis we distinguish four different fiscal scenarios by the combination of the three tax instruments. For the purpose of the analytical approach followed in this section, it is useful to simplify the analysis by restricting our discussion to fiscal scenarios in which only two tax instruments are simultaneously available for governments. This simplifies 
the analysis to a great extend, since only the first-order conditions of instruments chosen endogenously must simultaneously hold with strict equality in (2.16), whereas the condition of the unavailable instrument is redundant. In detail, for any combination of two taxes the optimal tax structures are given by:

$$
\begin{aligned}
\frac{t^{s}}{t^{r}}=\frac{\frac{\partial s}{\partial t^{r}} k-\frac{\partial s}{\partial t^{s}} s}{\frac{\partial k}{\partial t^{s}} s-\frac{\partial k}{\partial t^{r}} k} & \wedge & t^{w}=0 \\
\frac{t^{s}}{t^{w}}=\frac{\frac{\partial l}{\partial t^{w}} k-\frac{\partial l}{\partial t^{s}} l}{\frac{\partial k}{\partial t^{s}} l-\frac{\partial k}{\partial t^{w}} k} & \wedge & t^{r}=0 \\
\frac{t^{r}}{t^{w}}=\frac{\frac{\partial l}{\partial t^{r}} l-\frac{\partial l}{\partial t^{w}} s}{\frac{\partial s}{\partial t^{w}} s-\frac{\partial s}{\partial t^{r}}} & \wedge & t^{s}=0
\end{aligned}
$$

The last building block of our model is the Nash equilibrium on the international capital market which determines the effects of taxes on factor markets in (2.15)-(2.19). The Nash equilibrium is fully described by the first-order conditions of households [cf. eqs. (2.4)], firms [cf. eqs. (2.7)] and the market clearing condition:

$$
k^{i}-s^{i}+k^{a}-s^{a}=M^{i}+M^{a}=0 .
$$

where we introduce net capital imports $M \equiv k-s$ for further reference and indices $i, a$ in (2.20) to distinguish the two countries. Notice that we relegated the extensive derivations of comparative static effects of tax changes to the appendix. In the next section we use the comparative static reactions on national labor and the international factor markets in conditions (2.16) and yield the open economy's non-cooperative tax structures. It then goes to identify the effects of tax competition on these tax formulae, i.e. tax base and terms of trade effects.

\section{Basic Analytical Results}

We now turn to an analytical description of tax structures in the international Nash equilibrium between unequal countries. First, consider the case where governments are constrained not to levy wage taxes on the margin and only have access to both capital taxes. Inserting the comparative statics of the capital market [see equations (A.4)-(A.7) in the appendix] into condition (2.17) and employing (2.5), we yield the optimal tax structure from the perspective of a single government which is given by:

$$
\frac{t_{i}^{s}}{t_{i}^{r}}=\frac{f_{k k}^{i}\left[k^{i} \psi^{i}+M^{i}\left(\psi^{i}-l^{i} s_{r}^{i}\right)\right]}{f_{l l}^{i}\left(\phi^{i}+M^{i} L_{w}^{i}\right)-l^{i} k^{i}} .
$$

According to (3.1) the tax structure in a tax competition environment is ambiguous in sign, mainly due to the existence of (counteracting) tax base and terms of trade effects. For the following discussion it hence is useful to decompose (3.1) for both effects: 
- First, we can isolate tax base effects by restricting our analysis to the specific case of a symmetric Nash equilibrium between equal countries. It is well-known that there are no reasons for factor movements in a tax competition game between countries which are equal in every respect [i.e. $M^{i}=0$ ]. It follows that (3.1) simplifies to:

$$
\frac{t_{i}^{s}}{t_{i}^{r}}=\frac{f_{k k}^{i} k^{i} \psi^{i}}{f_{l l}^{i} \phi^{i}-l^{i} k^{i}}
$$

Equation (3.2) replicates equation (22) in Bucovetsky and Wilson (1991). It reconstructs their normative finding that a tax competition equilibrium in Nash strategies between identical countries is constrained efficient, if source- and residence-based capital taxes are available for governments. ${ }^{3}$ When the wage tax is absent, but both capital taxes are available for fiscal authorities, tax competition does not cause any additional distortions, given the available set of tax instruments. Also from a positive point (3.2) may be surprising, since both taxes are levied with positive rates in the symmetric Nash equilibrium. This seems to be in contrast with the analysis of Frenkel et al. (1991) in a small-country model that production taxes will not be levied when a residence-based capital tax is available in addition. As Bucovetsky and Wilson (1991) already pointed out, here the result is driven by the assumption of equal but also non-price-taking countries: Since the world interest rate is determined endogenously in this model, governments use the source-based capital tax as a substitute for the (unavailable) wage tax to tax away a part of labor income that can not be taxed directly.

- Second, we turn to the discussion of terms of trade effects which only occur when countries are unequal - hence $M^{i} \neq 0$ - and which are the cause of the overall ambiguity in (3.1). The basic intuition is that the crediting country [i.e. $M^{i}<0$ ] is interested in strategically lowering source-based capital taxes in order to relieve or even subsidize domestic investment. International capital supply is shortened by strategic tax policy and the level of international capital movements is reduced below the level in a freetrade equilibrium. Hence, the world interest rate rises and this depicts a terms of trade gain for the capital exporting country. Additionally, a positive residence-based capital tax strengthens the opportunity of the government to pursue strategic tax policy, since, on the one hand, this instrument further reduces national capital supply and, on the other hand, is sufficiently reliable to compensate for the loss in fiscal revenue caused by lowered source-based capital taxes. From the perspective of a capital importing country [i.e. $M^{i}>0$ ] incentives are mostly inverse. The government attempts to

\footnotetext{
${ }^{3}$ To prove this rigorously we have to re-interprete the model slightly. If the two countries are supposed to represent $n$ homogeneous countries, introducing $n$ in the capital market clearing condition (2.20) and performing the tax incidence analysis establishes that (3.2) is independent of $n$ in a symmetric Nash equilibrium.
} 
minimize international interest payments by strategically reducing the interest rate via a reduction of international capital movements below the free-trade level. Hence, to achieve a terms of trade gain, the capital importer aims at increasing home savings and reduces home capital demand. From that intuition, the fiscal authority reduces residence-based taxes or even subsidizes savings and simultaneously uses source-based capital taxes. Therefore, non-cooperative tax rates depend on the sign of the net capital balance. Since source-based capital taxes differ, production efficiency is not supported in a tax competition equilibrium between unequal countries.

So far we neglected the interactions on national labor markets in the interpretation of (3.1). The argumentation complicates considerably if general equilibrium effects of tax rate changes on labor supply (via own- and cross-price effects) are taken in account additionally. Nevertheless, our discussion revealed that two factors are dominant in an asymmetric Nash equilibrium: First, aggregate factor supply and demand elasticities - particularly of importance for tax base effects - and second, the sign of the net capital balance - which determines the consequences of changes in the world price for capital on national welfare.

From the course of the present discussion follows that there are clear limits for an analytical approach to determine the incentives of governments in an asymmetric Nash equilibrium when savings and labor supply decisions of individuals are subject to choice. ${ }^{4}$ We identified counteracting effects without giving quantitative estimates for overall tax structures. Moreover, complexity frustrates welfare analysis of decentral fiscal decisions since cooperative equilibria are difficult to determine analytically in a rather general framework. Straightforward, we set up a numerical analysis in order to weight counteracting effects on the one hand and provide normative results on the other.

\section{Numerical Analysis}

\subsection{Model Specification}

The numerical model is adopted from the theoretical section above. The specification of the production and utility functions is as follows. In each country output is generated according to the Cobb-Douglas production function:

$$
f(k, l)=k^{\alpha} l^{(1-\alpha)}, \quad 0<\alpha<1
$$

\footnotetext{
${ }^{4}$ Further analysis proved that the equations for non-cooperative tax structures in tax environments with a constrained set of fiscal instruments depicted by (2.18)-(2.19) get even more complicated than in (3.1) above. Moreover, it turned out that no additional insight can be reaped. Hence, we do not report these complex formulae in the paper.
} 
where technologies are identical across countries and the share of capital has been set at $\alpha=0.25$. This is a rough estimate for the distribution between capital and wage income in most OECD countries.

Preferences of the representative individual are of the constant elasticity of substitution (CES) form. An advantage of the CES specification is that this functional form allows to specify a variety of substitution elasticities between zero and infinity. The utility function in both countries is given by:

$$
U\left(x_{1}, x_{2}, F, g\right)=\left(\theta_{x_{1}}^{1 / \sigma} x_{1}^{\frac{\sigma-1}{\sigma}}+\theta_{x_{2}}^{1 / \sigma} x_{2}^{\frac{\sigma-1}{\sigma}}+\theta_{F}^{1 / \sigma} F^{j \frac{\sigma-1}{\sigma}}+\theta_{g}^{1 / \sigma} g^{\frac{\sigma-1}{\sigma}}\right)^{\frac{\sigma}{\sigma-1}},
$$

where the parameters $\theta$ denote the shares of second period's consumption, first periods' consumption, leisure consumption and public good supply. We abstract from differences in preferences and assume the utility function to be identical across countries. The adding-up

restriction for CES functions implies $\theta_{x_{1}}^{1 / \sigma}+\theta_{x_{2}}^{1 / \sigma}+\theta_{F}^{1 / \sigma}+\theta_{g}^{1 / \sigma}=1$. Therefore, we have one degree of freedom to choose the three ratios of shares.

In our specification we assume $\theta_{x_{2}} / \theta_{F}=4$. This ratio roughly corresponds to the weights calibrated by Ballard, Fullerton, Shoven and Whalley (1985:130) for a large-scale tax reform model based on U.S. data. Moreover we choose $\theta_{x_{2}} / \theta_{G}=4$ and $\theta_{x_{2}} / \theta_{x_{1}}=1$.11. The first ratio reflects that the share of government expenditures is about 25 percent of GDP in most OECD countries and the second roughly corresponds to the proportion of savings on total income. Sensitivity analyses have shown that our results are quite robust with respect to the specification of the shares. However, from the discussion in the previous section follows that the elasticity of substitution is supposed to be critical in our analysis. For the purpose of our aggregate substitution elasticity we consistently consider alternative scenarios with $\sigma=0.5$ and $\sigma \approx 1$, which cover most realistic cases.

\subsection{Numerical Results}

Numerical simulation experiments expand the preceding analysis in two respects: First, they allow to identify second-best efficient tax structures from an international perspective in an environment with a complete set of distorting taxes set in addition to fiscal scenarios in which governments only have access to a constrained set of two distortionary taxes. In our experiments we hence distinguish four different fiscal scenarios by the combination of the three instruments. Secondly, we obtain normative results in all four cases by comparing the tax competition equilibrium to the cooperative case when aggregated welfare of both countries is maximized.

From our discussion in the analytical section follows that tax base and terms of trade effects strongly affect non-cooperative tax structures. Whereas tax base effects show negative 
repercussions on national welfare under the usual assumptions on factor supply functions and produce positive fiscal externalities abroad, the welfare gains from terms of trade effects critically depend on the sign of the net capital balance: A reduction in the interest rate depicts a terms of trade gain for a capital importing country and a welfare loss for a capital exporting country. However, as also has become clear in the course of our hitherto discussion, the incentives of governments to use distorting taxes strategically are difficult to determine analytically. Non-surprisingly, terms of trade effects have often been neglected in the existing literature on capital tax competition. In the following numerical simulation experiments we thus emphasize the implications of terms of trade effects on tax structures and world efficiency. Our technique is to vary the distribution of residents between the two competing countries, given constant first period's national capital endowments.

\section{Only capital taxes available:}

In our first set of experiments we take up the scenario discussed in the analytical section. Table 1 and figure 1 portray consumption levels and tax rates in a tax competition game when per-capita capital endowment varies and fiscal authorities in both countries are constrained to only use capital taxes. Specifying an empirically plausible value for the difference in percapita endowments clearly is a difficult task, even if one accepts the two-country framework we have applied here. In table 1 we describe the differences in consumption levels of the four arguments in the utility function, which are expressed in percentage changes between Nash and cooperative equilibria. Initially, the capital exporting country has a per-capita capital endowment four times higher than the capital importing country (the ratio of sizes is $20: 80$ ), but then we lower this ratio in our experiments until both countries are equal (50:50). Turning first to the case in table 1 in which differences in per-capita capital endowments between both countries are most significant, we notice that consumption structures in the Nash equilibrium differ remarkably compared to a cooperative equilibrium when aggregated welfare is maximized. Local public goods are 'overprovided' in a capital exporting country and the standard tax competition result of an inefficient low level of public good provision is obtained in the capital importing country. Numerical results further confirm the intuition from the discussion in the analytical section that terms of trade effects are crucial for the incentives of governments between unequal countries to set taxes strategically. National capital supply is inefficient high in the capital importing country, whereas the government in the crediting country sets taxes to reduce savings of residents in order to achieve terms of trade gains.

According to table 1 inefficiencies shrink monotonously with decreasing differences between the competitors. The consumption structure in the symmetric Nash equilibrium between equal countries coincidences with the consumption structure in the efficient bench- 


\begin{tabular}{|c|c|c|c|c|c|c|c|}
\hline & & Symbol & $\operatorname{Size}^{a}$ & $g$ & $s$ & $F$ & $x_{2}$ \\
\hline \multirow{3}{*}{$\begin{array}{l}\text { Capital } \\
\text { country }\end{array}$} & \multirow[t]{3}{*}{ exporting } & ○ & 20 & 49.6 & -20.5 & 7.2 & 28.4 \\
\hline & & $\triangle$ & 30 & 23.9 & -18.7 & 3.7 & 13.8 \\
\hline & & $\nabla$ & 40 & 9.2 & -12.5 & 1.7 & 5.4 \\
\hline $\begin{array}{l}\text { Symmetric } \\
\text { equilibrium }\end{array}$ & Nash & $\star$ & 50 & 0 & 0 & 0 & 0 \\
\hline \multirow{3}{*}{$\begin{array}{l}\text { Capital } \\
\text { country }\end{array}$} & \multirow[t]{3}{*}{ importing } & $\nabla$ & 60 & -8.5 & 25.0 & -1.1 & -4.0 \\
\hline & & $\Delta$ & 70 & -16.2 & 97.8 & -2.1 & -7.0 \\
\hline & & $\bullet$ & 80 & -25.0 & - & -3.2 & -9.4 \\
\hline
\end{tabular}

${ }^{a}$ Share in population of a country at given world population

Table 1: Percentage changes in consumption levels between the Nash and cooperative equilibrium for different endowment patterns when only source-based and residence-based capital taxes are available.

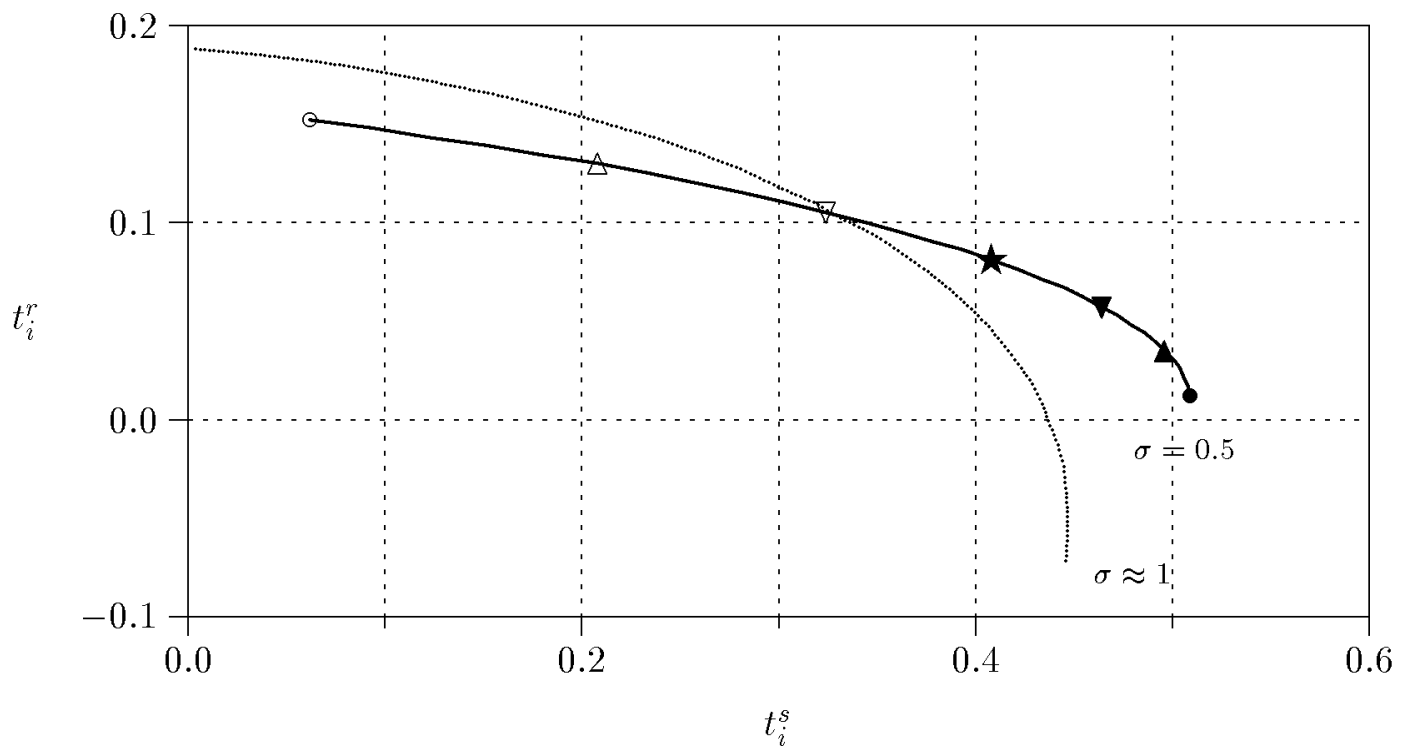

Note:

Tax structures in the capital exporting country: $\circ, \Delta$ and $\nabla$. The corresponding tax structures in the competing, capital importing country are represented by black symbols. The tax structure in the symmetric Nash equilibrium is depicted by point $\star$.

Figure 1: Tax rates $t_{i}^{s}, t_{i}^{r}$ conditional on per-capita endowment and elasticity of substitution $\sigma$. 
mark. Our simulations hence reproduce the result established by Bucovetsky and Wilson (1991): Decentralized fiscal decisions lead to an efficient Nash equilibrium even in the absence of wage taxes, provided countries are identical in all respects. The intuition is that the source-based capital tax serves well as a substitute for the missing wage tax. Hence, the government has the necessary set of taxes available to support an efficient allocation in the decentral Nash equilibrium. Our numerical simulations also indicate, however, that an efficient allocation is not supported if countries are unequal.

Curve $\sigma=0.5$ in figure 1 describes the effect of international inequalities in per-capita endowments on non-cooperative tax structures. The capital exporting country sets the residence-based capital tax at a high rate, whereas the source-based capital tax is set at a low level by the government when compared to the tax rates chosen by the competitor. The intuition here is that a capital exporting country maximizes interest payments accruing from the debtor. The creditor country can achieve a terms of trade gain by strategically reducing home savings and promoting home investment. Turning to the incentives in a capital importing country, we notice from figure 1 that the government reduces residence-based capital taxes and increases source-based capital taxes in order to lower the world interest rate by reducing net capital imports. Since source-based capital taxes differ between the two countries, the marginal productivity of capital is not equalized internationally and production efficiency is not supported in the asymmetric Nash equilibrium. In contrast, terms of trade effects are irrelevant when countries are equal. Tax rates are levied at equal, positive rates under the CES specification of the utility function. Hence, the international capital allocation must be efficient and this is in accordance with our discussion of (3.2) in the analytical section.

Sensitivity analysis shows that results do not change qualitatively if the elasticity of substitution is set from $\sigma=0.5$ to a perhaps unrealistic high value of $\sigma \approx 1$. In figure 1 this is reflected by a shift of the curve which influences tax rates but does not change tax structures fundamentally. ${ }^{5}$

\section{Only source-based capital and wage taxes available:}

In our second fiscal scenario we assume that source-based capital and wage taxes are in the set of instruments available for governments, but fiscal authorities are restricted in their access to residence-based capital taxes. From table 2 we obtain the standard tax competition result that local public goods are underprovided. This result holds independently of the sign of net capital balance, but is most significant in the case of a large capital exporter [first

\footnotetext{
${ }^{5}$ Of course, if $\sigma$ approaches zero, a case sensibly excluded here, taxes on consumption are lump-sum. In this case the government can choose wage and residence-based capital taxes arbitrarily. In a first-best scenario, tax competition will not be a problem.
} 


\begin{tabular}{lrrrrrr}
\hline & Symbol & Size $^{a}$ & $g$ & $s$ & $F$ & $x_{2}$ \\
\hline Capital exporting coun- & $\circ$ & 20 & -7.4 & -0.9 & 3.9 & 7.0 \\
try & $\triangle$ & 30 & -4.6 & 0.9 & 5.1 & 4.3 \\
& $\nabla$ & 40 & -3.1 & 3.5 & 5.0 & 2.8 \\
Symmetric Nash equilib- & $\star$ & 50 & -2.3 & 6.5 & 4.2 & 1.2 \\
rium & & & & & & \\
Capital importing coun- & $\mathbf{\nabla}$ & 60 & -1.5 & 10.5 & 3.1 & 0.3 \\
try & $\mathbf{\Delta}$ & 70 & -1.5 & 14.9 & 1.8 & -0.5 \\
& $\bullet$ & 80 & -1.5 & 29.2 & 0.7 & -0.5
\end{tabular}

${ }^{a}$ Share in population of a country at given world population

Table 2: Percentage changes in consumption levels between the Nash and cooperative equilibrium for different endowment patterns when only source-based capital and wage taxes are available.

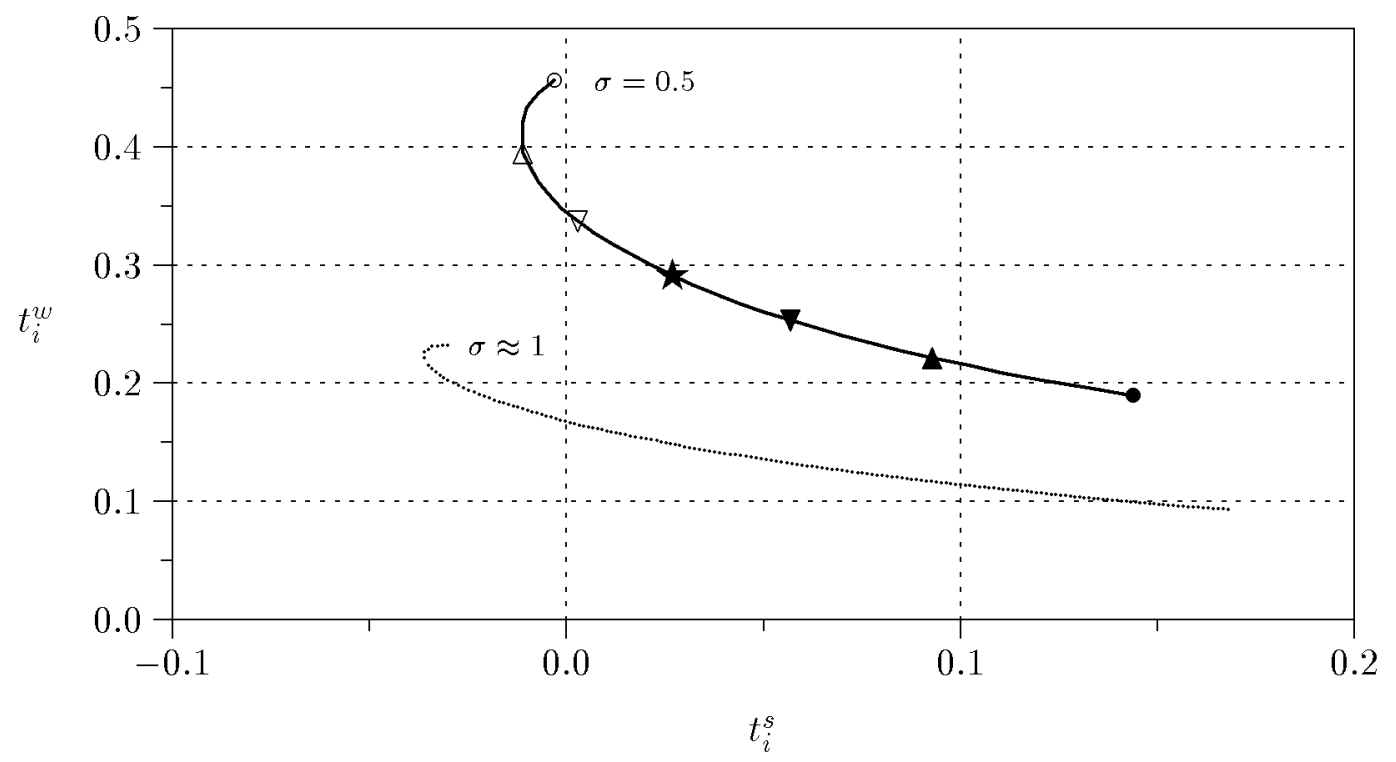

Note:

Tax structures in the capital exporting country: $\circ, \Delta$ and $\nabla$. The corresponding tax structures in the competing, capital importing country are represented by black symbols. The tax structure in the symmetric Nash equilibrium is depicted by point $\star$.

Figure 2: Tax rates $t_{i}^{s}, t_{i}^{w}$ conditional on per-capita endowment and elasticity of substitution $\sigma$. 
row in table 2], in which consumption levels of all private goods rise clearly (compared to the cooperative benchmark) in exchange to public good provision. We therefore conclude that tax base effects dominate terms of trade effects in this scenario. Nevertheless, terms of trade effects are observed, which is suggested by the fact that the increase in per-capita national savings is higher in a capital importing country as compared to the capital exporters' situation.

In contrast, terms of trade effects are irrelevant in the symmetric Nash equilibrium. The level of public good provision, however, is not efficient. The intuition is that the government can not effectively tax the incomes of all factors subject to choice by residents: The sourcebased capital tax serves well as a substitute for a missing wage tax (as has become clear from the discussion of our first experiment), but is unsuitable to replace a tax on savings income. ${ }^{6}$

The curve $\sigma=0.5$ in figure 2 represents the locus of tax structures for varying per-capita endowments. It confirms our intuition that terms of trade and tax base effects of sourcebased capital and wage taxes tend to work in the same direction in a capital exporting country, but the effect of wage taxes on the net capital balance is comparatively weak. In fact, the wage tax first distorts the national labor market and hence has only an indirect effect on the capital intensity in private production. This argument is confirmed by the result that the wage tax is used in first line in order to generate public revenue. The incentives for a fiscal authority in the capital importing country are inverse. Here, source-based capital taxes generate terms of trade gains since they lower national capital demand. ${ }^{7}$

\section{Only residence-based capital and wage taxes available:}

In the third scenario, depicted by table 3 and figure 3 , governments are assumed to only rely on residence-based capital and wage taxes, but not on source-based capital taxes. In contrast to our results in the first case, here it is the capital importing country where local public goods are provided at an inefficient high level, whereas the government in the capital exporting country underprovides the public good according to table 3. Moreover, demands for all private goods (except for first period's consumption) are inefficiently low in the capital exporting country. Hence, the results summarized in table 3 suggest that the capital exporter looses in the Nash equilibrium compared to the cooperative equilibrium and the capital importing country gains. We will verify that intuition in our subsequent

\footnotetext{
${ }^{6}$ Hence, wage income effectively carries the burden of public spending. Consistently, leisure consumption and savings increase in the symmetric case of table 2 .

${ }^{7}$ The curve in figure 2 is backward bending for a large capital exporter. At a high level of international capital movements the rate of capital tax is increased by the government in order to maximize terms of trade effects and not to hamper international capital movements 'too' much.
} 


\begin{tabular}{lcccccc}
\hline & Symbol & Size $^{a}$ & $g$ & $s$ & $F$ & $x_{2}$ \\
\hline Capital exporting & $\circ$ & 20 & -2.2 & -4.9 & -8.8 & -0.8 \\
country & $\triangle$ & 30 & -1.2 & -4.7 & -5.1 & -0.4 \\
& $\nabla$ & 40 & -0.4 & -3.2 & -2.1 & -0.2 \\
Symmetric Nash & $\star$ & 50 & 0 & 0 & 0 & 0 \\
equilibrium & & & & & & \\
Capital importing & $\boldsymbol{\nabla}$ & 60 & 0.5 & 5.1 & 2.0 & 0.3 \\
country & $\boldsymbol{\Delta}$ & 70 & 1.0 & 12.4 & 3.2 & 0.8 \\
& $\bullet$ & 80 & 1.6 & 25.1 & 4.4 & 1.7
\end{tabular}

${ }^{a}$ Share in population of a country at given world population

Table 3: Percentage changes in consumption levels between the Nash and cooperative equilibrium for different endowment patterns when only residence-based capital and wage taxes are available.

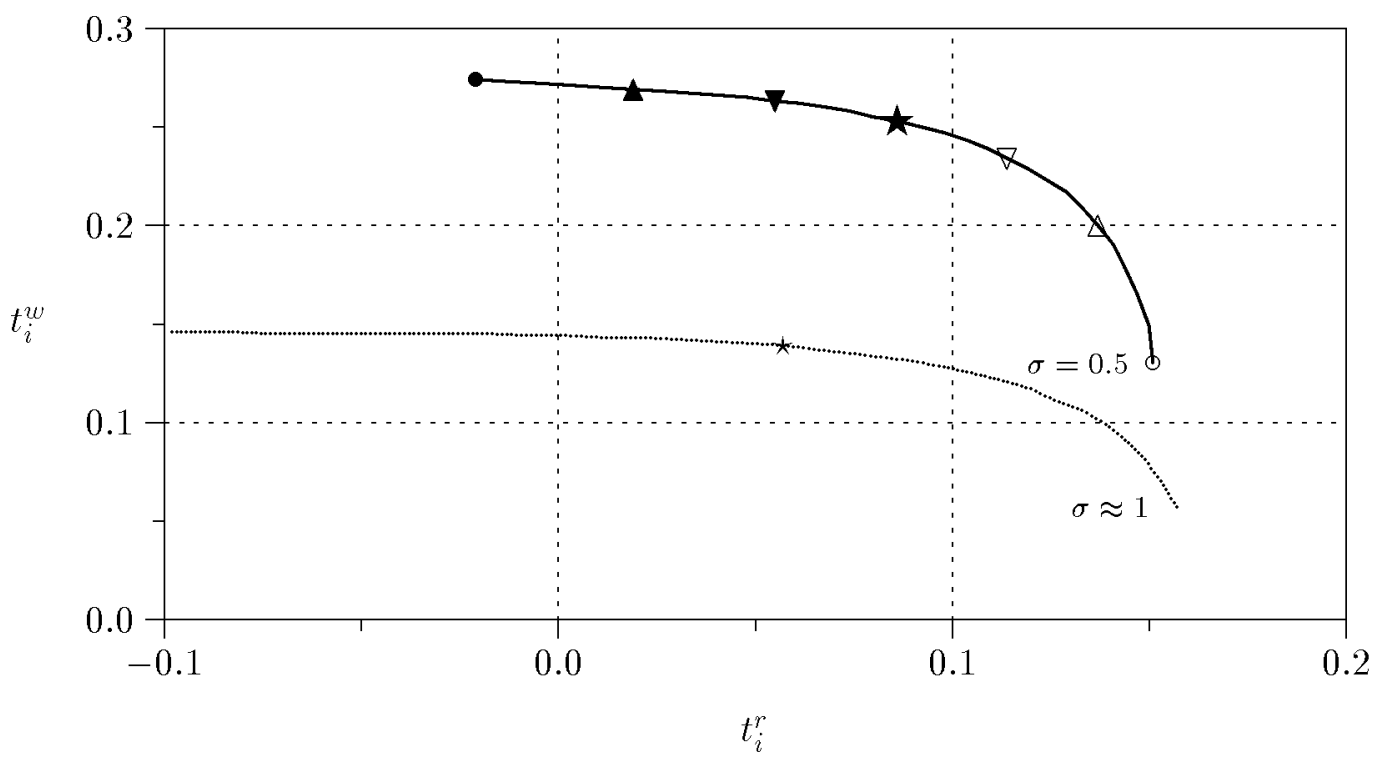

Note:

Tax structures in the capital exporting country: $\circ, \Delta$ and $\nabla$. The corresponding tax structures in the competing, capital importing country are represented by black symbols. The tax structure in the symmetric Nash equilibrium is depicted by point $\star$.

Figure 3: Tax rates $t_{i}^{r}, t_{i}^{w}$ conditional on per-capita endowment and elasticity of substitution $\sigma$. 
discussion about the incentives of governments to vote in favor of a consistent international tax agreement. Also notice that inefficiencies decrease in direction towards a symmetric Nash equilibrium when both countries are equal in all respects.

Figure 3 depicts the tax structures in the tax competition game. The government in a capital exporting country subsidizes labor supply (which increases the productiveness of home capital investment) and levies residence-based capital taxes (which causes a discrepancy between the net interest rate and the rate of time preference) in order to shorten international capital supply.

In the symmetric case, however, terms of trade effects become irrelevant and taxes on the incomes of both factors subject to choice are levied efficiently in the decentral Nash equilibrium. This result is in fact very closely related to the Production Efficiency lemma. Aggregate consumption is on the economy's production frontier in this case, since the government can levy taxes on the incomes of all factors subject to choice by households. If per-capita capital endowment falls in addition to the symmetric case, the wage tax is set almost independently of the capital tax. A capital importer strategically relieves or subsidizes national per-capita savings in order to increase international capital supply, which means to effectively use terms of trade effects. It is reasonable that the capital importer gains from tax competition in this fiscal environment, since the fiscal revenue of the wage tax is sufficient reliable to subsidize savings optimally from the government's point of view. To summarize, we conclude that tax competition equilibria generally are inefficient in this case in which residence-based capital taxes exist and the international capital allocation is undistorted (since source-based capital taxes are absent).

\section{Unconstrained set of taxes available:}

Finally, we discuss the case in which an unconstrained set of fiscal instruments is available for fiscal authorities. Table 4 and figure 4 portray consumption levels and tax structures in the asymmetric Nash equilibrium conditional to per-capita endowments. As in the previous case, local public goods are provided at an inefficient low level in a capital exporting country and are provided at an inefficient high level in a capital importing country. However, inefficiencies are reduced in direction towards the symmetric Nash equilibrium. This result is confirmed by the study of Eggert (1998) who proves analytically that a tax competition equilibrium in residence-based capital and wage taxes between large countries is second-best efficient if countries are equal in all respects.

Turning to the tax structures it is obvious from figure 4 that source-based capital taxes are not levied by governments in a tax competition game between equal countries. Governments rely on residence-based capital and wage taxes, which only distort consumption but not production decisions. However, production efficiency is not supported in asymmet- 


\begin{tabular}{lrrrrr}
\hline & Size $^{a}$ & $g$ & $s$ & $F$ & $x_{2}$ \\
\hline Capital exporting & 20 & -10.4 & -5.8 & -15.4 & -10.2 \\
country & 30 & -5.9 & -4.5 & -7.9 & -6.2 \\
& 40 & -2.6 & -2.5 & -3.2 & -2.9 \\
Symmetric Nash & 50 & 0 & 0 & 0 & 0 \\
equilibrium & & & & & \\
Capital importing & 60 & 2.0 & 3.0 & 2.0 & 2.1 \\
country & 70 & 2.6 & 6.9 & 3.2 & 3.6 \\
& 80 & 3.8 & 12.4 & 3.7 & 4.2
\end{tabular}

${ }^{a}$ Share in population of a country at given world population

Table 4: Percentage changes in consumption levels between the Nash and cooperative equilibrium for different endowment patterns when the set of fiscal instruments is unconstrained.

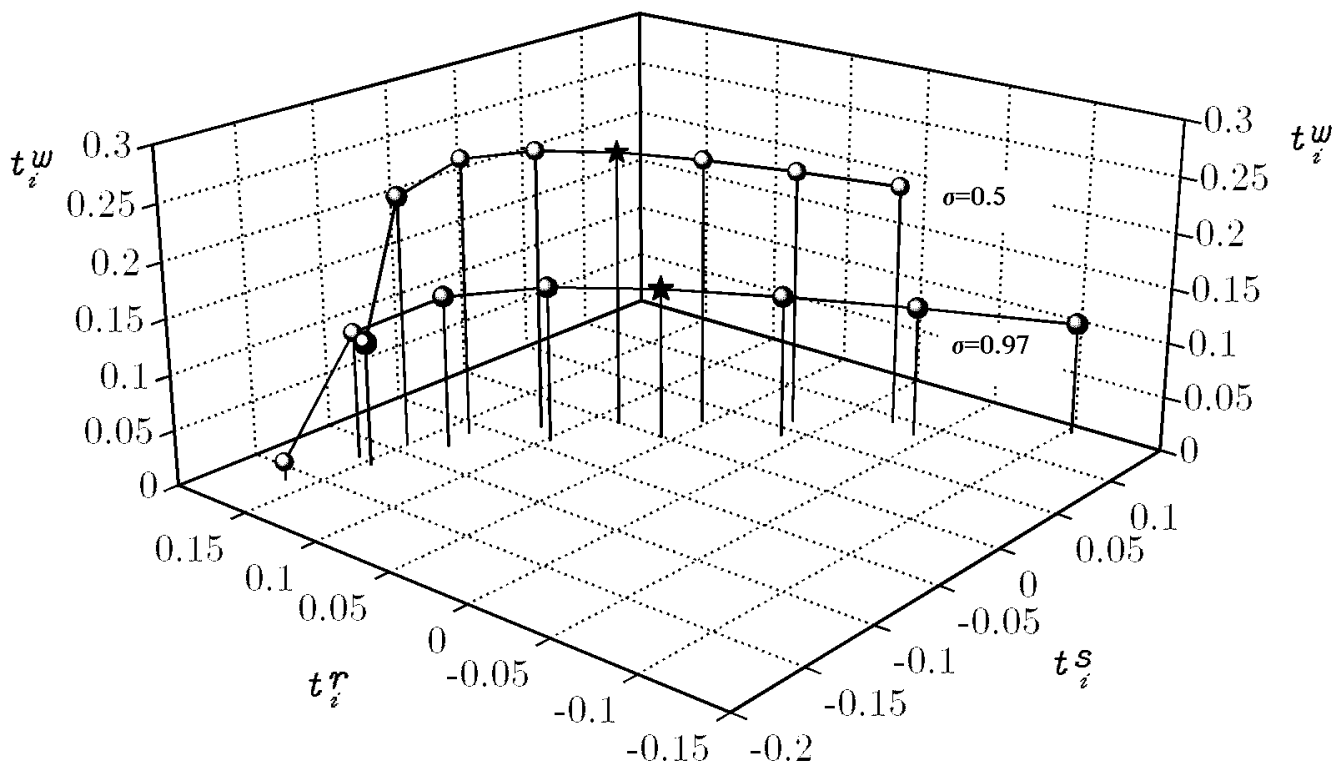

Note:

Per-capita capital endowment decreases from the left to the right, the tax structure in the symmetric Nash equilibrium is depicted by stars $\star$

Figure 4: Tax rates $t_{i}^{s}, t_{i}^{r}, t_{i}^{w}$ conditional on per-capita endowment and elasticity of substitution $\sigma$. 


\begin{tabular}{|c|c|c|c|c|}
\hline case & $\begin{array}{l}\text { x system } \\
\text { instruments }\end{array}$ & $\begin{array}{c}\text { two iden- } \\
\text { tical countries }\end{array}$ & $\begin{array}{l}\text { capital impor- } \\
\text { ting country }\end{array}$ & $\begin{array}{l}\text { capital expor- } \\
\text { ting country }\end{array}$ \\
\hline $\mathrm{a}$ & $t_{i}^{s}, t_{i}^{r}$ & $313.740 \quad(0)$ & $276.506(-14.6)$ & $469.200(30.6)$ \\
\hline $\mathrm{b}$ & $t_{i}^{s}, t_{i}^{w}$ & $369.628(-0.2)$ & $335.247(-1.3)$ & $489.529(1.9)$ \\
\hline $\mathrm{c}$ & $t_{i}^{r}, t_{i}^{w}$ & $370.301 \quad(0)$ & $324.854(\approx 0)$ & $547.639(-1.2)$ \\
\hline $\mathrm{d}$ & $t_{i}^{s}, t_{i}^{r}, t_{i}^{w}$ & $370.301 \quad(0)$ & $325.801 \quad(2.3)$ & $529.103(-8.7)$ \\
\hline
\end{tabular}

${ }^{a}$ Population share of 80 percent on world population.

${ }^{b}$ Population share of 20 percent on world population.

Table 5: Per-capita utility levels in tax competition scenarios (deviation to cooperative equilibria in parentheses)

ric Nash equilibria, because source-based capital taxes are used strategically and hence at different rates: The capital exporting country subsidizes home capital investment and the capital importing country levies positive source-based capital taxes due to terms of trade considerations. The marginal productivity of capital is not equalized internationally. Hence, aggregated world production is not maximized. Governments also use residence-based capital taxes in order to affect terms of trade strategically. The capital exporter cuts back on net capital exports by taxing domestic savings, whereas the capital importer aims at reducing net capital imports and subsidizes domestic savings. In contrast, governments of both countries set taxes on the income of internationally immobile labor at positive rates. This result should be intuitive, since the strategic effect of the wage tax instrument on the net capital balance is dominated by direct taxes on capital.

Lastly turning to table 5 we discuss the question whether unequal countries have incentives to vote in favor of a uniform international system for direct taxes. According to our results a capital importing country prefers the Nash equilibrium in labor and source-based capital taxes to all other non-cooperative cases [row b in table 5] and should reject any proposal to effectively enforce taxes on worldwide interest income. This is in clear contrast to the results in the symmetric Nash equilibria [the first column in table 5] which would predict that competing countries reach an agreement to effectively enforce international taxation of interest income according to the residence principle. But the prediction of the symmetric models that countries agree to effectively enforce residence-based capital taxes is 
not supported by reality. ${ }^{8}$

\section{Conclusions}

This paper has focused on the optimal mix of direct taxes when a country faces domestic or international constraints on the set of available tax instruments. It has been shown that, due to the existence of pecuniary and fiscal externalities, the opening of a country's borders not necessarily expands a country's consumption possibilities.

In a theoretical analysis of asymmetric Nash equilibria between large countries terms of trade and tax base effects were isolated as important factors which considerably determine the incentives for a country to act strategically. However, the analytical approach was obviously limited due to the complex model structure. Therefore, numerical simulation experiments of the model were used in order to weight the counteracting effects on the tax rates and to implement a welfare analysis for each scenario. The simulation results indicated that the advantageous features of residence-based capital taxes known from the previous literature about tax competition games between symmetric countries do not carry over to the asymmetric case. In all four fiscal scenarios terms of trade effects caused an inefficiency of the decentralized Nash equilibrium, whether or not residence-based capital taxes are available for fiscal authorities. However, a precautionary note is appropriate if results are taken as a guide for international tax policy since it also turned out that no systematic welfare gains can be reaped from distorting production decisions via source-based capital taxes.

Therefore there may still be a case for residence-based capital taxes which only distort consumption decisions but not production decisions. However, from a positive point of view, our numerical results indicated that - given only wage taxes and source-based capital taxes are in the set of available tax instruments - a capital importing country might frustrate international efforts to establish residence-based taxes. In contrast, a capital exporting country is better off in the non-cooperative equilibrium with a full tax instrument set, compared to a Nash equilibrium when only wage and source-based capital taxes are available. This country has an incentive to vote in favor of mutual tax assistance. However, the prediction is that without compensating transfer payments - international compliance for such an assistance might not be easy to reach.

\footnotetext{
${ }^{8}$ From table 5 it is seen that the two equal countries obtain a higher welfare level in the symmetric tax competition equilibrium in $t_{i}^{s}, t_{i}^{w}$ than in the case $t_{i}^{s}, t_{i}^{r}$. However, the symmetric Nash equilibrium in $t_{i}^{s}, t_{i}^{w}$ is inefficient. This demonstrates the value of a numerical analysis, which allows to order the Nash equilibria by welfare levels.
} 


\section{A Appendix}

The basic purpose of the appendix is to derive the comparative static effects in the Nash equilibrium on the international capital market. In the open economy, factors supplied and demanded can be derived as implicit functions from the first-order conditions of households (2.4), firms (2.7), the market clearing conditions for national labor and the international capital market. Complete differentiation yields the following equation system:

$$
\begin{aligned}
\frac{\partial L^{j}}{\partial w^{j}} d w^{j}+\frac{\partial L^{j}}{\partial t_{j}^{w}} d t_{j}^{w}+\frac{\partial L^{j}}{\partial r} d r+\frac{\partial L^{j}}{\partial t_{j}^{r}} d t_{j}^{r}-d L^{j} & =0 & & \forall j \in\{i, a\}, \\
\frac{\partial s^{j}}{\partial w^{j}} d w^{j}+\frac{\partial s^{j}}{\partial t_{j}^{w}} d t_{j}^{w}+\frac{\partial s^{j}}{\partial r} d r+\frac{\partial s^{j}}{\partial t_{j}^{r}} d t_{j}^{r}-d s^{j} & =0 & & \forall j \in\{i, a\}, \\
f_{l l}^{j} d l^{j}+f_{l k}^{j} d k^{j}-d w^{j} & =0 & & \forall j \in\{i, a\}, \\
f_{k l}^{j} d l^{j}+f_{k k}^{j} d k^{j}-d r-d t_{j}^{s} & =0 & & \forall j \in\{i, a\}, \\
d l^{j}-d L^{j} & =0 & & \forall j \in\{i, a\}, \\
d k^{i}-d s^{i}+d k^{a}-d s^{a} & =0 . & &
\end{aligned}
$$

We use the identities:

$$
\begin{array}{ll}
\frac{\partial L^{j}}{\partial t_{j}^{r}} \equiv-\frac{\partial L^{j}}{\partial r}, & \frac{\partial L^{j}}{\partial t_{j}^{w}} \equiv-\frac{\partial L^{j}}{\partial w^{j}}, \\
\frac{\partial s^{j}}{\partial t_{j}^{r}} \equiv-\frac{\partial s^{j}}{\partial r}, & \frac{\partial s^{j}}{\partial t_{j}^{w}} \equiv-\frac{\partial s^{j}}{\partial w^{j}},
\end{array}
$$

and substitute $d w^{j}, d r, d L^{j}$ in (A.1a)-(A.1b) for the full expressions (A.1c)-(A.1e) which gives:

$$
\begin{aligned}
& L_{w}^{j}\left(f_{l l}^{j} d l^{j}+f_{l k}^{j} d k^{j}\right)-L_{w}^{j} d t_{j}^{w}+L_{r}^{j}\left(f_{k l}^{j} d l^{j}+f_{k k}^{j} d k^{j}-d t_{j}^{s}\right)-L_{r}^{j} d t_{j}^{r}-d l^{j}=0 \quad \forall j \in\{i, a\}, \\
& s_{w}^{j}\left(f_{l l}^{j} d l^{j}+f_{l k}^{j} d k^{j}\right)-s_{w}^{j} d t_{j}^{w}+s_{r}^{j}\left(f_{k l}^{j} d l^{j}+f_{k k}^{j} d k^{j}-d t_{j}^{s}\right)-s_{r}^{j} d t_{j}^{r}-d s^{j}=0 \quad \forall j \in\{i, a\}, \\
& f_{k l}^{i} d l^{i}+f_{k k}^{i} d k^{i}-d t_{i}^{s}-f_{k l}^{a} d l^{a}-f_{k k}^{a} d k^{a}+d t_{a}^{s}=0, \\
& d k^{i}-d s^{i}+d k^{a}-d s^{a}=0 .
\end{aligned}
$$


From (2.5) and (2.9) this equation system can be written in matrices as follows:

$$
\begin{aligned}
& \left(\begin{array}{cccccc}
-\frac{f_{k k}^{i}}{l^{i}}\left(\phi^{i}+M^{i} L_{w}^{i}\right) & 0 & 0 & 0 & \frac{f_{l l}^{i}}{k^{i}}\left(\phi^{i}+M^{i} L_{w}^{i}\right)-1 & 0 \\
0 & -\frac{f_{k k}^{a}}{l^{a}}\left(\phi^{a}+M^{a} L_{w}^{a}\right) & 0 & 0 & 0 & \frac{f_{l l}^{a}}{k^{a}}\left(\phi^{a}+M^{a} L_{w}^{a}\right)-1 \\
\frac{f_{k k}^{i}}{l^{i}}\left(\psi^{i}+M^{i} s_{w}^{i}\right) & 0 & -1 & 0 & -\frac{f_{l l}^{i}}{k^{i}}\left(\psi^{i}-M^{i} s_{w}^{i}\right) & 0 \\
0 & \frac{f_{k k}^{a}}{l^{a}}\left(\psi^{a}+M^{i} s_{w}^{i}\right) & 0 & -1 & 0 & -\frac{f_{l l}^{a}}{k^{a}}\left(\psi^{a}-M^{a} s_{w}^{a}\right) \\
f_{k k}^{i} & -f_{k k}^{a} & 0 & 0 & -f_{l l}^{i} \frac{l^{i}}{k^{i}} & f_{l l}^{a} \frac{l^{a}}{k^{a}} \\
1 & 1 & -1 & -1 & 0 & 0
\end{array}\right) \\
& \times\left(\begin{array}{c}
d k^{i} \\
d k^{a} \\
d s^{i} \\
d s^{a} \\
d l^{i} \\
d l^{a}
\end{array}\right)=\left(\begin{array}{ccc}
L_{r}^{i} & L_{r}^{i} & L_{w}^{i} \\
0 & 0 & 0 \\
s_{r}^{i} & s_{r}^{i} & s_{w}^{i} \\
0 & 0 & 0 \\
0 & 1 & 0 \\
0 & 0 & 0
\end{array}\right)\left(\begin{array}{c}
d t_{i}^{r} \\
d t_{i}^{s} \\
d t_{i}^{w}
\end{array}\right)
\end{aligned}
$$

We notice that the determinant of the Hessian on the left hand side of (A.2) is:

$$
\begin{aligned}
|\mathfrak{H}|= & k^{a} k^{i} l^{a}\left[f_{k k}^{a}+f_{k k}^{i}-f_{l l}^{a} f_{k k}^{i} \frac{\phi^{a}-L_{w}^{a} M^{i}}{k^{a}}-\right. \\
& \left.f_{k k}^{a} f_{l l}^{i} \frac{\phi^{i}+L_{w}^{i} M^{i}}{k^{i}}-f_{k k}^{a} f_{k k}^{i}\left(\frac{\psi^{a}+s_{w}^{a} M^{i}}{l^{a}}+\frac{\psi^{i}-s_{w}^{i} M^{i}}{l^{i}}\right)\right],
\end{aligned}
$$

where $M^{i}=-M^{a}$ has been used.

Assume $|\mathfrak{H}| \neq 0$. Applying Cramer's rule to (A.2) we yield the effects of the international capital market in response to changes in the tax rates:

$$
\begin{aligned}
\frac{\partial k^{i}}{\partial t_{i}^{s}} & =\left\{k^{i} l^{a}\left[k^{a}-f_{l l}^{i} k^{a}\left(l^{i} L_{r}^{i}+M^{i} L_{w}^{i}+\phi^{i}\right)+f_{l l}^{a}\left(M^{i} L_{w}^{a}-\phi^{a}\right)\left(1-\frac{f_{l l}^{i}}{k^{i}}\left(l^{i} L_{r}^{i}+L_{w}^{i} M^{i}+\phi^{i}\right)\right)\right]\right. \\
& -f_{k k}^{a} k^{a} k^{i}\left(\psi^{a}+M^{i} s_{w}^{a}+l^{a} s_{r}^{i}\right)+f_{k k}^{a} f_{l l}^{i} k^{a}\left(l^{i} L_{r}^{i} \psi^{a}+\phi^{i} \psi^{a}+l^{a} L_{r}^{i} \psi^{i}+l^{a} \phi^{i} s_{r}^{i}\right) \\
& \left.+f_{k k}^{a} f_{l l}^{i} k^{a} M^{i}\left(L_{w}^{i} \psi^{a}+l^{i} L_{r}^{i} s_{w}^{a}+L_{w}^{i} M^{i} s_{w}^{a}+\phi^{i} s_{w}^{a}+l^{a} L_{w}^{i} s_{r}^{i}-l^{a} L_{r}^{i} s_{w}^{i}\right)\right\} \frac{1}{|\mathfrak{H}|} \\
\frac{\partial k^{i}}{\partial t_{i}^{r}} & =\left\{f_{l l}^{a} f_{l l}^{i} l^{a} l^{i} L_{r}^{i}\left(\phi^{a}-L_{w}^{a} M^{i}\right)+k^{a} l^{a}\left(f_{l l}^{i} l^{i} L_{r}^{i}+f_{k k}^{a} k^{i} s_{r}^{i}\right)\right. \\
& \left.+f_{k k}^{a} f_{l l}^{i} k^{a} l^{i}\left[L_{r}^{i}\left(\psi^{a}+M^{i} s_{w}^{a}\right)+s_{r}^{i}\left(\phi^{i}+L_{w}^{i} M^{i}\right)+L_{r}^{i}\left(\psi^{i}-M^{i} s_{w}^{i}\right)\right]\right\} \frac{1}{|\mathfrak{H}|} .
\end{aligned}
$$




$$
\begin{aligned}
\frac{\partial s^{i}}{\partial t_{i}^{s}} & =\left\{\left(\psi^{i}-M^{i} s_{w}^{i}\right)\left(\frac{f_{k}^{i} k}{l^{i}}+\frac{f_{k k}^{a} f_{l l}^{i}}{k^{i}} L_{r}^{i}\right)+f_{l l}^{a} f_{k k}^{i}\left(\phi^{a}-M^{i} L_{w}^{a}\right) \frac{l^{i} s_{r}^{i}-\phi^{a}}{k^{a} l^{i}}-s_{r}^{i}\left(f_{k k}^{a}+f_{k k}^{i}\right)\right. \\
& +f_{k k}^{a} f_{k k}^{i}\left[M^{i} \frac{\psi^{a} s_{w}^{i}-\psi^{i} s_{w}^{a}}{l^{a} l^{i}}+s_{r}^{i} \frac{\psi^{a}+s_{w}^{a} M^{i}}{l^{a}}-\psi^{a} \psi^{i}-M^{i^{2}} s_{w}^{a} s_{w}^{i}\right] \\
& \left.+f_{k k}^{a} f_{l l}^{i} s_{r}^{i} \frac{\phi^{i}+L_{w}^{i} M^{i}}{k^{i}}+f_{l l}^{a} f_{k k}^{i} M^{i} s_{w}^{i} \frac{\phi^{a}-L_{w}^{a} M^{i}}{k^{a} l^{i}}\right\} \frac{k^{a} k^{i} l^{a}}{|\mathfrak{H}|} \\
\frac{\partial s^{i}}{\partial t_{i}^{r}} & =\left\{f_{l l}^{a} f_{k k}^{i} s_{r}^{i} \frac{\phi^{a}-L_{w}^{a} M^{i}}{k^{a}}-s_{r}^{i}\left(f_{k k}^{a}+f_{k k}^{i}\right)+f_{k k}^{a} f_{l l}^{i} s_{r}^{i} \frac{\phi^{i}+L_{w}^{i} M^{i}}{k^{i}}\right. \\
& \left.+f_{k k}^{a} f_{k k}^{i} s_{r}^{i} \frac{\psi^{a}+M^{a} s_{w}^{a}}{l^{a}}+f_{k k}^{a} f_{l l}^{i} L_{r}^{i} \frac{\psi^{i}-s_{w}^{i}}{k^{i}}\right\} \frac{k^{a} k^{i} l^{a}}{|\mathfrak{H}|}
\end{aligned}
$$




\section{References}

Ballard, C.L., D. Fullerton, J. Shoven, and J. Whalley (1985) A general equilibrium model for tax policy evaluation (Chicago: The University of Chicago Press)

Bucovetsky, S. (1991) 'Asymmetric tax competition.' Journal of Urban Economics 30, 167181

Bucovetsky, S., and J.D. Wilson (1991) 'Tax competition with two tax instruments.' Regional Science and Urban Economics 21, 333-350

DePater, J.A., and G.M. Myers (1994) 'Strategic capital tax competition: A pecuniary externality and a corrective device.' Journal of Urban Economics 36, 66-78

Diamond, P.A., and J.A. Mirrlees (1971) 'Optimal taxation and public production.' American Economic Review 61, 8-27 and 261-278

Eggert, W. (1998) 'Capital tax competition with three tax instruments.' Forthcoming Zeitschrift für Wirtschafts- und Sozialwissenschaften

Eggert, W., and A. Haufler (1998) 'Capital taxation and the production efficiency theorem.' Forthcoming Economics Letters

Frenkel, J.A., A. Razin, and E. Sadka (1991) International taxation in an integrated world (London: Massachusetts Institute of Technology Press)

Homburg, S. (1998) 'Competition and co-ordination in international capital income taxation.' mimeo

Keen, M., and H. Piekkola (1997) 'Simple rules for the optimal taxation of international capital income.' Scandinavian Journal of Economics 99, 447-461

Wildasin, D.E. (1989) 'Interjurisdictional capital mobility: Fiscal externality and a corrective subsidy.' Journal of Urban Economics 25, 193-212

Wilson, J.D. (1991) 'Tax competition with interregional differences in factor endowments.' Regional Science and Urban Economics 21, 423-451

Zodrow, G.R., and P. Mieszkowski (1986) 'Pigou, Tiebout, property taxation and the underprovision of local public goods.' Journal of Urban Economics 19, 356-370 